\title{
Estudo das propriedades do ferro fundido cinzento com adição de nióbio para
}

\section{trabalho a quente}

\author{
Study of the properties of gray cast iron with added niobium for hot work \\ Estudio de las propiedades del hierro fundido gris con niobio añadido para trabajos en caliente
}

Recebido: 01/09/2021 | Revisado: 08/09/2021 | Aceito: 03/10/2021 | Publicado: 04/10/2021

\author{
Marcos Paulo Meira \\ ORCID: https://orcid.org/0000-0001-7313-2053 \\ Universidade de Uberaba, Brasil \\ E-mail: marcosmeira1@uol.com; marcos.meira@cbmm.com \\ Euclides Antônio Pereira de Lima \\ ORCID: https://orcid.org/0000-0002-7649-1040 \\ Universidade Federal de Uberlândia, Brasil \\ E-mail: euclides.lima@uniube.br \\ Francisco Manoel Perez do Nascimento \\ ORCID: https://orcid.org/0000-0003-4500-8818 \\ Universidade Federal de Minas Gerais, Brasil \\ E-mail: francisco.manoel@metaprol.com.br
}

\begin{abstract}
Resumo
Um dos principais materiais utilizados na fabricação de peças automobilísticas é o ferro fundido cinzento. Este material é amplamente utilizado na fabricação de discos de freios. A proposta deste estudo foi avaliar o comportamento mecânico e físico de quatro ligas de ferro fundido cinzento de matriz perlítica. Para tanto, quatro ligas denominadas: liga base, liga base $+0,10 \% \mathrm{Nb}$, liga base $+0,20 \% \mathrm{Nb}$ e liga base $+0,15 \% \mathrm{Mo}$, foram fundidas e posteriormente avaliadas quanto à: composição química, resistência à tração nas temperaturas de $22^{\circ} \mathrm{C}, 380^{\circ} \mathrm{C}, 480^{\circ} \mathrm{C}, 580^{\circ} \mathrm{C}$ e $680^{\circ} \mathrm{C}$, dureza, microestrutura e difusividade térmica. Nos ensaios de resistência à tração nas temperaturas de $22^{\circ} \mathrm{C}$ a $680^{\circ} \mathrm{C}$, pôde-se observar que quando adicionados na liga base, os elementos nióbio e molibdênio elevam o limite de resistência do ferro fundido cinzento, pois são formadores de carbonetos e promovem o refino da perlita. A adição de $\mathrm{Nb}$ ou Mo elevou também a dureza das ligas em relação à liga base. Com relação à microestrutura, foi possível observar também que as ligas com adição de Nb ou Mo apresentaram grafita levemente mais refinada que a liga base. Através dos ensaios de difusividade, pôde-se observar que a liga denominada liga base $+0,10 \% \mathrm{Nb}$ apresenta um resultado melhor de difusividade em todas as temperaturas testadas $\left(380^{\circ} \mathrm{C}, 480^{\circ} \mathrm{C}, 580^{\circ} \mathrm{C}\right.$ e $\left.680^{\circ} \mathrm{C}\right)$. Este fato pode ser atribuído à maior quantidade de grafita e à adição de nióbio no teor de $0,10 \%$.
\end{abstract}

Palavras-chave: Ferro fundido cinzento; Nióbio; Molibdênio; Disco de freio.

\begin{abstract}
One of the main materials used in the production of automobile parts is gray cast iron. This material is widely used in the production of brake discs. The aim of this study was to evaluate the mechanical and physical behavior of four pearlitic gray cast iron alloys. For this purpose, four alloys named: base alloy, base alloy $+0.10 \% \mathrm{Nb}$, base alloy + $0.20 \% \mathrm{Nb}$ and base alloy $+0.15 \% \mathrm{Mo}$, were cast and subsequently evaluated for: chemical composition, tensile strength at temperatures of $22^{\circ} \mathrm{C}, 380^{\circ} \mathrm{C}, 480^{\circ} \mathrm{C}, 580^{\circ} \mathrm{C}$ and $680^{\circ} \mathrm{C}$, hardness, microstructure and thermal diffusivity. In tensile strength tests at temperatures from $22^{\circ} \mathrm{C}$ to $680^{\circ} \mathrm{C}$, it was observed that when added to the base alloy, the elements niobium and molybdenum increase the strength limit of gray cast iron, as they form carbides and promote the refining of perlite. The addition of $\mathrm{Nb}$ or Mo also increased the hardness of the alloys in relation to the base alloy. Regarding the microstructure, it was also possible to observe that the alloys with the addition of $\mathrm{Nb}$ or Mo had slightly more refined graphite. Diffusivity tests showed that the base cast iron $+0.10 \% \mathrm{Nb}$ has better diffusivity results at all tested temperatures $\left(380^{\circ} \mathrm{C}, 480^{\circ} \mathrm{C}, 580^{\circ} \mathrm{C}\right.$, and $\left.680^{\circ} \mathrm{C}\right)$. This fact may be associated with the increased amount of graphite and the addition of $0.10 \%$ niobium content.
\end{abstract}

Keywords: Gray cast iron; Niobium; Molybdenum; Break discs.

\section{Resumen}

Uno de los principales materiales en la fabricación de piezas de automóvil es el hierro fundido gris, material utilizado en la fabricación de discos de freno. El propósito de este estudio fue evaluar el comportamiento mecánico y físico de cuatro aleaciones de hierro fundido gris perlítico. Para ello, se moldearon cuatro aleaciones denominadas aleación base, aleación base $+0,10 \% \mathrm{Nb}$, aleación base $+0,20 \% \mathrm{Nb}$ y aleación base $+0,15 \% \mathrm{Mo}$, y posteriormente se evaluaron para: composición química, resistencia a la tracción a temperaturas de $22^{\circ} \mathrm{C}, 380^{\circ} \mathrm{C}, 480^{\circ} \mathrm{C}, 580^{\circ} \mathrm{C}$ y $680^{\circ} \mathrm{C}$, dureza, 
microestructura y difusividad térmica. En ensayos de resistencia a la tracción a temperaturas de $22^{\circ} \mathrm{C}$ a $680{ }^{\circ} \mathrm{C}$, se observó que al agregarse a la aleación base, los elementos niobio o molibdeno aumentan la dureza de la fundición gris, ya que son fuertes formadores de carburos de alta dureza y promueven el refinamiento de la perlita. En cuanto a la microestructura, se pudo observar que la matriz metálica es muy similar para todas las aleaciones, con tendencia a disminuir el tamaño del grafito cuando se agregan los elementos niobio o molibdeno. Através de las pruebas de difusividad se pudo observar que la aleación denominada aleación base $+0,10 \% \mathrm{Nb}$ presenta un mejor resultado de difusividad a todas las temperaturas probadas $\left(380^{\circ} \mathrm{C}, 480^{\circ} \mathrm{C}, 580^{\circ} \mathrm{C} \mathrm{y} 680^{\circ} \mathrm{C}\right)$. Este hecho se puede atribuir a la mayor cantidad de grafito y la adición de niobio en el contenido de $0,10 \%$.

Palabras clave: Fundición gris; Nióbio; Molibdeno; Disco de freno.

\section{Introdução}

Os produtos siderúrgicos comuns são ligas de ferro-carbono com teores de $0 \%$ a 4,5\% de carbono, sendo os produtos mais conhecidos o aço e o ferro fundido. Os aços contêm de $0 \%$ a $2 \%$ de carbono, já os ferros fundidos contêm teores de carbono entre $2 \%$ e $4,5 \%$. O ferro fundido pertence a um grupo importante e fundamental para a indústria. Devido ao maior teor de carbono, sua temperatura de fusão é menor que a do aço, fato que reduz o custo de produção (energia e refratário), além de permitir a fundição de peças complexas difíceis de serem obtidas através de outros processos (Colpaert, 1983).

Um dos principais mercados de aplicação de ferro fundido é o automobilístico, que nos últimos anos veem possibilitando a redução considerável de consumo de combustível através da redução de peso de seus componentes. Desta forma, a engenharia recebe uma responsabilidade ainda maior na busca de soluções eficientes na redução de peso dos automóveis. Os projetos mecânicos de otimização para a redução das cotas de seus componentes necessitam utilizar materiais que suportem as solicitações do novo projeto. Para tanto, os materiais selecionados devem ter uma resistência mecânica elevada, suportando as cargas ou tensões a que serão submetidos. Outro ponto fundamental é a resistência à temperatura de trabalho a que os componentes são expostos. Essas variáveis serão parte fundamental deste trabalho que tem como objetivo determinar o limite máximo de resistência à tração às temperaturas de $22^{\circ} \mathrm{C}, 380^{\circ} \mathrm{C}, 480^{\circ} \mathrm{C}, 580^{\circ} \mathrm{C}$ e $680^{\circ} \mathrm{C}$, em quatro diferentes tipos de ferros fundidos cinzentos denominados: liga base; liga base com adição de $0,10 \%$ de $\mathrm{Nb}$; liga base com adição de $0,20 \%$ de $\mathrm{Nb}$ e liga base com adição de $0,15 \%$ de Mo. O entendimento da composição química é fundamental para elevar a resistência mecânica e à fadiga térmica do ferro fundido. Quando se deseja obter determinadas propriedades, as variáveis mais importantes a considerar isoladamente são a composição química e os elementos de liga adicionados. Os principais elementos presentes nos ferros fundidos são: carbono, silício, enxofre, fósforo, cobre, manganês, estanho, cromo, níquel, antimônio e molibdênio.

O nióbio tem sido considerado como um elemento de liga para ferros fundidos que promove melhorias na resistência mecânica à temperatura ambiente e à elevadas temperaturas. Vários autores investigaram a influência da adição de nióbio para ferros fundidos, principalmente a classe dos grafíticos, onde ele proporciona o refino das células eutéticas e diminuição do espaçamento interlamelar da perlita (ZHAI et al., 2011). Mohrbacher (2011), relatou que a adição de Nb diminui o diâmetro médio das células eutéticas para testes realizados com adição de $0,042 \% \mathrm{Nb}$ e $0,29 \% \mathrm{Nb}$. Constatou também que a redução do diâmetro médio das células é mais forte na faixa de $0,2 \% \mathrm{Nb}$. O mecanismo de refinamento da grafita pode ser explicado considerando que pequenos carbonetos de $\mathrm{NbC}$ precipitam e crescem em partículas maiores. Contudo, é inevitável que alguns pequenos precipitados residuais de $\mathrm{NbC}$ permaneçam durante o resfriamento até a temperatura eutética, atuando como locais de nucleação heterogênea para o crescimento da grafita na reação eutética. Como resultado, o aumento da taxa de nucleação resulta em grafita de morfologia mais refinada. Outro aspecto importante é que o nióbio diminui a difusão do carbono durante a solidificação, o que também restringe o crescimento da grafita. A Figura 1 apresenta o efeito da adição de nióbio no aumento da dureza e na redução do desgaste no ferro fundido. 
Figura 1 - Efeito da adição de nióbio no aumento da dureza e na redução do desgaste no ferro fundido.

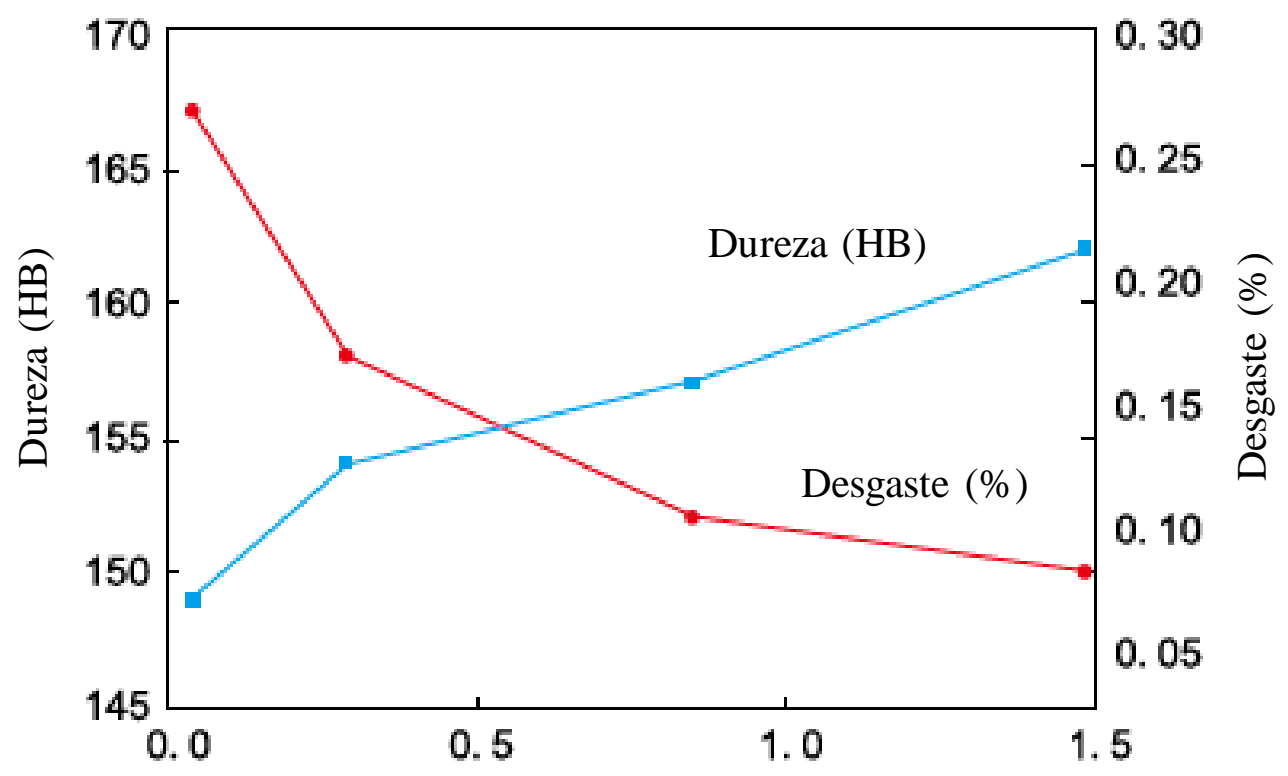

Nióbio contido $(\%)$

Fonte: Zhai et al. (2009).

A condutividade térmica é uma das principais propriedades físicas a ser observada, especialmente em componentes que trabalham sob fadiga térmica, como cabeçotes de motores e discos de freios. O ferro fundido cinzento possui uma maior condutividade térmica em relação aos outros ferros fundidos grafíticos pois possui a grafita paralela ao plano basal (Hasse,1996).

De acordo com a norma europeia DIN EN 1561/1997, o coeficiente de dilatação térmica não é afetado pela classe de ferro fundido cinzento, enquanto a condutividade térmica aumenta à medida que se caminha para classes de menor de resistência mecânica. Isto é devido à contribuição da grafita na condutividade térmica, de modo que as classes que contém maiores quantidades de grafita apresentam maior condutividade térmica, e consequentemente, menor resistência mecânica.

Nos ferros fundidos cinzentos, a resistência à tração decresce levemente com o aumento da temperatura até $200^{\circ} \mathrm{C}$, e ocorre um leve aumento na resistência à tração em torno de $400^{\circ} \mathrm{C}$. Para temperaturas superiores a $400^{\circ} \mathrm{C}$, a resistência cai acentuadamente.

A formação da grafita influencia diretamente nas propriedades térmicas do ferro fundido cinzento, material deste estudo. Segundo Wang (1999), verificou-se que a difusividade térmica do ferro fundido cinzento aumenta com o carbono equivalente e tem uma forte correlação linear com o comprimento da grafita. O aumento no tamanho da grafita resulta em um aumento significativo na difusividade térmica. O aumento da difusividade térmica melhora as propriedades do material ao transferir calor, sendo fundamental no dimensionamento de discos de freios automobilísticos. Por meio da obtenção de resultados de difusividade, pode-se calcular a condutividade térmica. Discos de freios com elevada condutividade térmica apresentam melhor resistência à nucleação e à propagação de trincas térmicas.

\section{Material e Métodos}

Visando avaliar a influência da adição de nióbio no ferro fundido cinzento para trabalho a quente, foram produzidas quatro ligas diferentes para estudo, sendo uma delas a liga base utilizada na produção de discos de freios automobilísticos. As adições dos elementos de liga foram realizadas em forno de indução e foram produzidos discos de freios para retirada de corpos de prova para ensaios mecânicos e químicos. 


\subsection{Material}

Para a realização dos testes comparativos das ligas de ferros fundidos cinzentos aplicados a discos de freios automobilísticos, foram elaboradas quatro composições químicas. A Tabela 1 apresenta a especificação da liga base. As cargas das corridas foram constituídas de ferro-gusa e barras de aço, sendo que as barras de aço laminado de um mesmo lote para garantir a homogeneidade da composição. A Tabela 2 apresenta a variação dos elementos de liga deste estudo.

Tabela 1 - Composição química da base prevista para testes $(\%)$.

\begin{tabular}{lcccccccccc} 
Limites & $\mathbf{C}$ & Si Base & Si Inoc & Mn & P & S & Cr & Cu & Sn & Ceq \\
\hline Mín. & 3,70 & 1,45 & 1,75 & 0,40 & 0,00 & 0,08 & 0,10 & 0,30 & 0,02 & 4,30 \\
\hline Máx. & 3,75 & 1,50 & 1,80 & 0,50 & 0,05 & 0,10 & 0,15 & 0,35 & 0,03 & 4,37 \\
\hline Meta & 3,72 & 1,47 & 1,77 & 0,45 & 0,00 & 0,09 & 0,13 & 0,33 & 0,025 & 4,34 \\
\hline
\end{tabular}

Fonte: Autor (2020).

Tabela 2 - Variações dos elementos químicos mantendo a composição base (\%).

\begin{tabular}{ccccc}
\hline Limites (\%) & Teste 1 & Teste 2 & Teste 3 & Teste 4 \\
& Nb ou Mo & Nb & Mo & 0,14 \\
\hline Mín. & 0,00 & 0,08 & 0,18 & 0,16 \\
\hline Máx. & 0,00 & 0,12 & 0,22 & 0,15 \\
\hline Meta & 0,00 & 0,10 & 0,20 & \\
\hline
\end{tabular}

Fonte: Autor (2020).

\subsection{Dimensionais e equipamentos}

Os materiais das ligas foram fundidos e aquecidos até aproximadamente $1480^{\circ} \mathrm{C}$ em forno à indução, com carga de 120 $\mathrm{kg}$. Os corpos de prova para caracterizações metalográficas e das propriedades mecânicas foram retirados de discos de freios automobilísticos produzidos de acordo com a Figura 2. Os corpos de prova para análise química foram produzidos em molde metálico.

Figura 2 - Desenho e molde dos discos de freios automobilístico utilizado como corpo de prova.

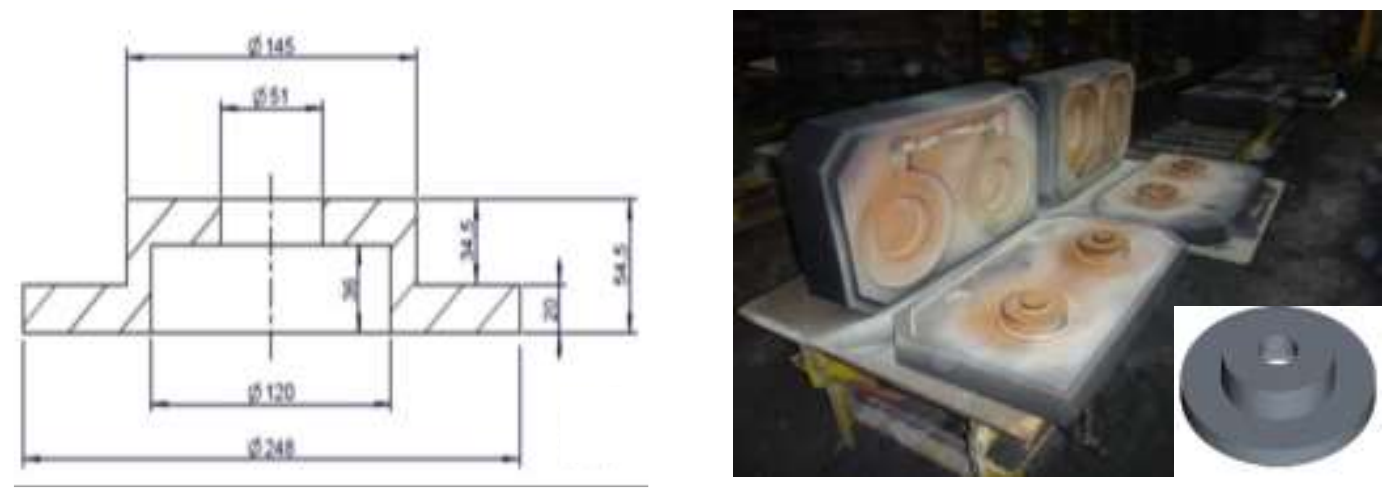

Fonte: [Adaptado de] Relatório Senai Sistema FIEMG (2020).

\subsection{Métodos}

Foram elaboradas 4 corridas para a produção dos discos automobilísticos. A sequência de carregamento das matérias primas e dos insumos, é descrita abaixo:

1. Fez-se o carregamento do forno utilizando-se ferro-gusa e barras de aço; 
2. Assim que o ferro fundido liquefez, com a temperatura em torno de $1200^{\circ} \mathrm{C}$, realizou-se a limpeza com retirada da escória, adicionou-se os elementos de ligas e elevou-se a temperatura a $1400^{\circ} \mathrm{C}$ para manter o banho líquido e evitar inclusões;

3. Coletou-se amostra para análise química com manutenção da temperatura a $1400^{\circ} \mathrm{C}$;

4. Coletou-se amostra para análise térmica;

5. Elevação da temperatura até $1470^{\circ} \mathrm{C}$, transferência do metal do forno para a panela e a inoculação no jato de metal líquido;

6. Vazamento do metal da panela para o molde a uma temperatura de 1370 a $1420^{\circ} \mathrm{C}$. Este controle foi realizado visando padronizar a temperatura de vazamento para os discos das 4 ligas;

7. Os discos de freios foram desmoldados após quarenta e cinco minutos, para padronização do tempo de resfriamento.

Foram usinadas 200 amostras distribuídas nas 4 composições químicas de ferros fundidos cinzentos estudados. Ensaios de tração foram realizados até a ruptura em cinco temperaturas diferentes. O planejamento da distribuição de temperaturas de ensaios está apresentado no Tabela 3.

Tabela 3 - Quantificação de corpos de prova para testes e temperatura de ensaios por tipo de corrida.

\begin{tabular}{|c|c|c|c|c|}
\hline Ensaio & Liga base & $\begin{array}{c}\text { Liga Base + } \\
0,10 \% \text { Nb }\end{array}$ & $\begin{array}{c}\text { Liga Base + } \\
0,20 \% \mathrm{Nb}\end{array}$ & $\begin{array}{c}\text { Liga Base + } \\
0,15 \% \text { Mo }\end{array}$ \\
\hline & \multicolumn{4}{|c|}{ Número de corpos de prova } \\
\hline Tração Ambiente & 10 & 10 & 10 & 10 \\
\hline Tração $380^{\circ} \mathrm{C}$ & 10 & 10 & 10 & 10 \\
\hline Tração $480^{\circ} \mathrm{C}$ & 10 & 10 & 10 & 10 \\
\hline Tração $580^{\circ} \mathrm{C}$ & 10 & 10 & 10 & 10 \\
\hline Tração $680^{\circ} \mathrm{C}$ & 10 & 10 & 10 & 10 \\
\hline Total de Corpos de Prova & 50 & 50 & 50 & 50 \\
\hline
\end{tabular}

Fonte: Autor (2020).

\section{Resultados}

\subsection{Ensaios de resistência à tração}

Os ensaios de resistência à tração foram realizados em 5 diferentes temperaturas: $22^{\circ} \mathrm{C}, 380^{\circ} \mathrm{C}, 480^{\circ} \mathrm{C}, 580^{\circ} \mathrm{C}$ e $680^{\circ} \mathrm{C}$. O equipamento utilizado para realização dos ensaios de tração em elevadas temperaturas foi o modelo universal de ensaios de tração com faixa nominal de $1000 \mathrm{kN}$. A taxa aproximada de aplicação de força foi de $3,7 \mathrm{~mm} / \mathrm{min}$ permitindo uma variação da temperatura de aproximadamente $3^{\circ} \mathrm{C}$. Os ensaios de tração em temperatura ambiente foram realizados em máquina de tração tipo EMIC modelo DL 10000 com capacidade de 100 kN. Pôde-se observar que ao se adicionar os elementos de liga nióbio e molibdênio no ferro fundido cinzento, ocorreu um acréscimo na resistência à tração em todas as temperaturas nas quais foram realizados os ensaios. De acordo com a literatura, o comportamento dos ferros fundidos cinzentos apresenta um leve aumento da resistência na temperatura em torno de $400^{\circ} \mathrm{C}$ e decresce acentuadamente em temperaturas maiores. Este comportamento pode ser evidenciado nos testes de resistência à tração em diferentes temperaturas.

As Figuras 3, 4, 5 e 6 mostram os comparativos dos resultados de resistência à tração das quatro ligas deste estudo, em diferentes temperaturas. 
Research, Society and Development, v. 10, n. 13, e68101320112, 2021

(CC BY 4.0) | ISSN 2525-3409 | DOI: http://dx.doi.org/10.33448/rsd-v10i13.20112

Figura 3 - Comparativo dos resultados médios de resistência à tração em diferentes temperaturas.

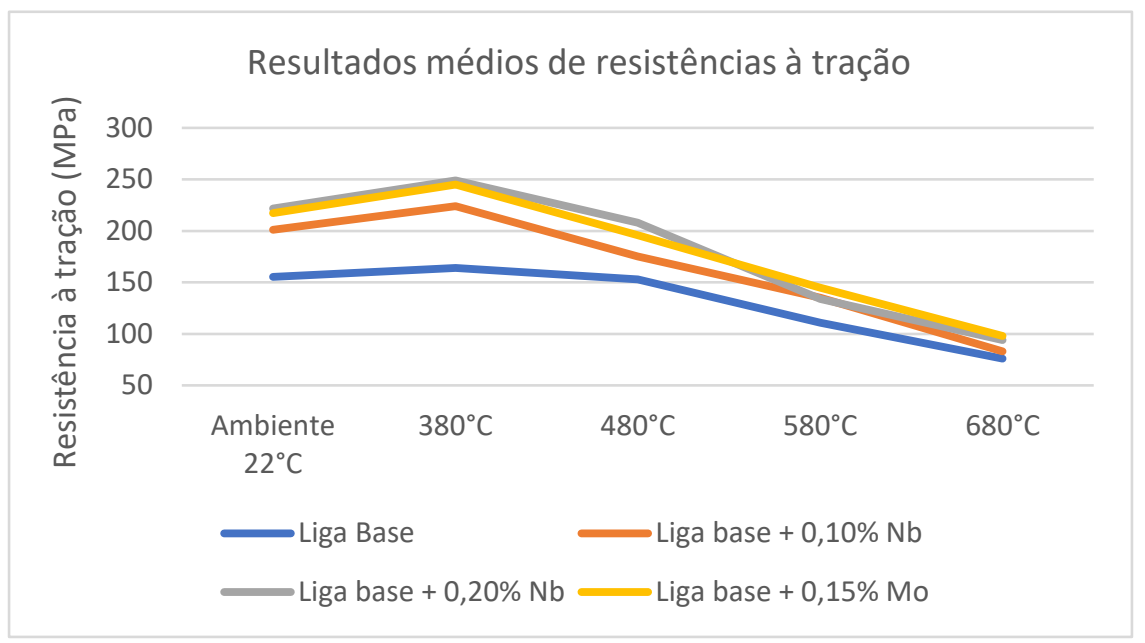

Fonte: Autor (2020).

Figura 4 - Resultados da análise de resistência máxima à tração na temperatura de $480^{\circ} \mathrm{C}$ em corpos de prova retirados de disco de freio bruto de fusão.

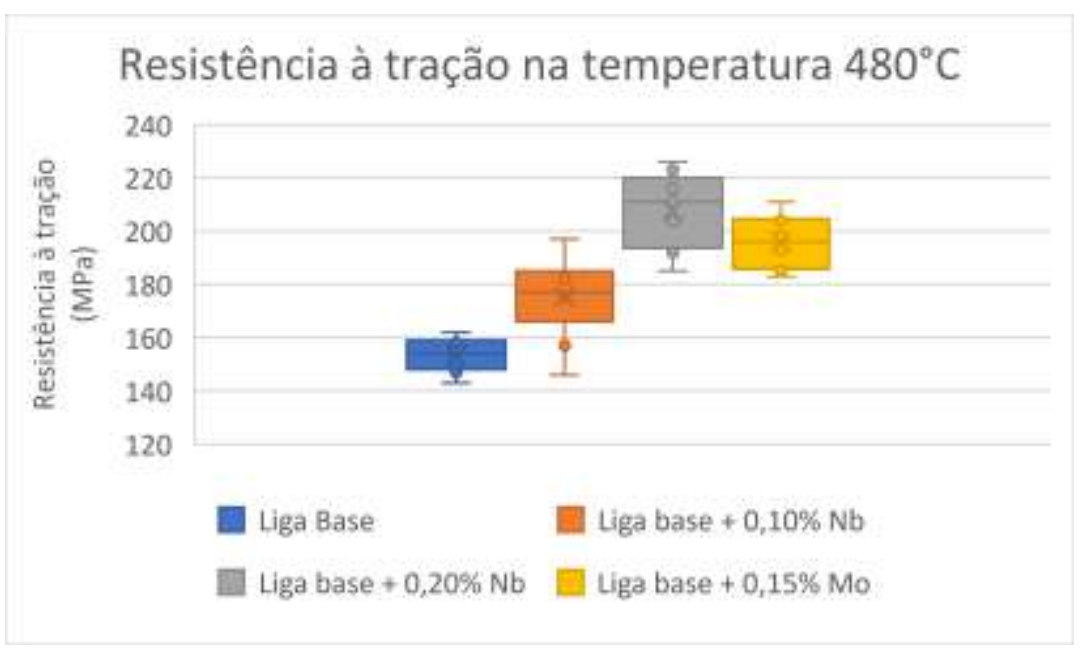

Fonte: Autor (2020).

Figura 5 - Resultados da análise de resistência máxima à tração na temperatura de $580^{\circ} \mathrm{C}$ em corpos de prova retirados de disco de freio bruto de fusão.

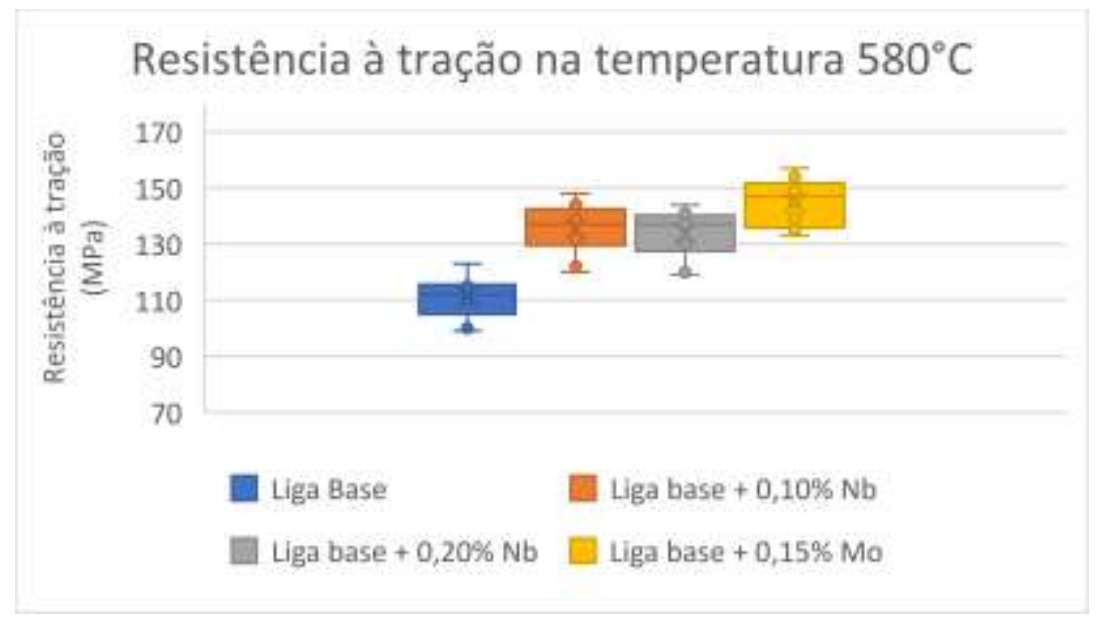

Fonte: Autor (2020). 
Figura 6 - Resultados da análise de resistência máxima à tração na temperatura de $680^{\circ} \mathrm{C}$ em corpos de prova retirados de disco de freio bruto de fusão.

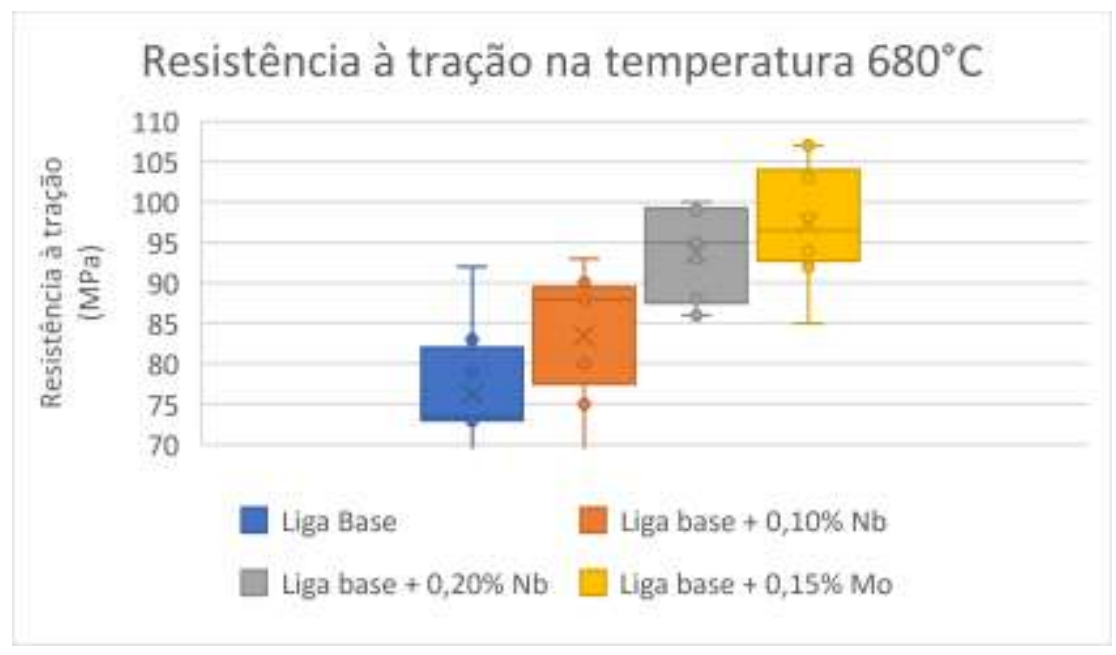

Fonte: Autor (2020).

\subsection{Ensaios de dureza brinell}

O teste 3 da liga de ferro fundido cinzento (liga base) com adição de 0,20\% de $\mathrm{Nb}$ apresentou melhor resultado de resistência à tração nas temperaturas ambiente, $380^{\circ} \mathrm{C}$ e $480^{\circ} \mathrm{C}$. Para os testes realizados em temperaturas de $580^{\circ} \mathrm{C}$ e $680^{\circ} \mathrm{C}, \mathrm{o}$ melhor resultado apresentado foi no teste 4 , da liga de ferro fundido cinzento (liga base) com adição de $0,15 \%$ de Mo. O teste 2 , da liga de ferro fundido cinzento (liga base) com adição de $0,10 \%$ de $\mathrm{Nb}$, apresentou bons resultados em todas as temperaturas dos testes realizados, podendo ser uma excelente alternativa econômica para aplicações susceptíveis a temperaturas elevadas, principalmente até temperaturas de trabalho de $580^{\circ} \mathrm{C}$.

A Figura 7 mostra os resultados dos ensaios de dureza Brinell realizados em amostras retiradas dos discos de freios de acordo com cada composição.

Figura 7 - Resultados do ensaio de dureza Brinell da amostra da pista dos discos de freio.

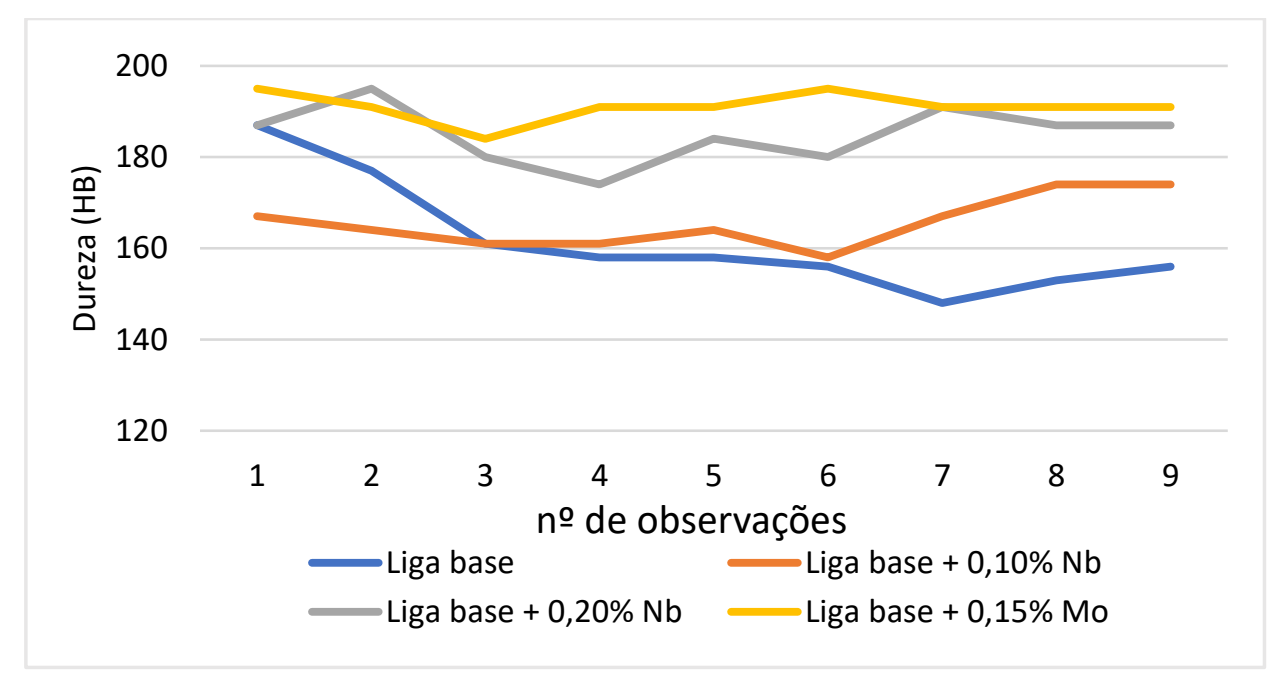

Fonte: Autor (2020).

Pôde-se observar que, na liga base, houve um aumento na dureza Brinell ao se adicionar elementos de liga como nióbio e molibdênio, pois são elementos que formam carbonetos de alta dureza. Estes elementos promovem também o refino do espaço interlamelar da perlita, o que contribui também para elevar os resultados de dureza. 


\subsection{Análise microestrutural}

Os principais fatores que influenciam a transferência de calor nos ferros fundidos cinzentos são a distribuição, o tamanho e a morfologia da grafita, sendo que os veios de grafita possuem condutividade térmica maior que a matriz perlítica. Wang (1999) afirma que a morfologia e a geometria dos flocos de grafita afetam a difusividade no ferro cinzento e, em amostras com carbono equivalente constante, o comprimento médio e máximo dos flocos tem uma forte correlação linear com difusividade térmica: quanto mais grafita por área maior a difusividade.

$\mathrm{Na}$ análise da microestrutura pode-se observar que a liga base apresentou ausência de grafitas do tipo E. Entretanto, nas corridas com nióbio e molibdênio, mesmo que em raras proporções, estas foram observadas. Em relação ao tamanho das grafitas, observa-se que o nióbio e o molibdênio tendem à diminuição dos seus tamanhos, e há uma leve tendência do nióbio a concentrar mais a distribuição das grafitas entre os tamanhos de 3 a 6 . A matriz metálica é muito similar para todas as corridas, mesmo com a variação de temperatura que as amostras tiveram nos testes de resistência à tração em temperaturas elevadas $\left(380^{\circ} \mathrm{C}, 480^{\circ} \mathrm{C}\right.$, $580^{\circ} \mathrm{C}$ e $\left.680^{\circ} \mathrm{C}\right)$

Zhai et al. (2011) indicam, por meio de resultados experimentais, que o aumento da adição de nióbio (até um certo nível) refina a grafita e a célula eutética, e reduz o espaçamento interlamelar perlítico causado principalmente pela diminuição da temperatura eutetóide. Além disso, a adição de nióbio ocasionou uma formação de fase dura rica em carboneto de nióbio que efetivamente aumentou a dureza e a resistência ao desgaste. As Figuras 8 a 11 mostram as análises metalográficas de acordo com cada composição.

Figura 8 - Análise metalográfica para o corpo de prova de liga base sem ataque (a) e com ataque Nital 5\% (b).
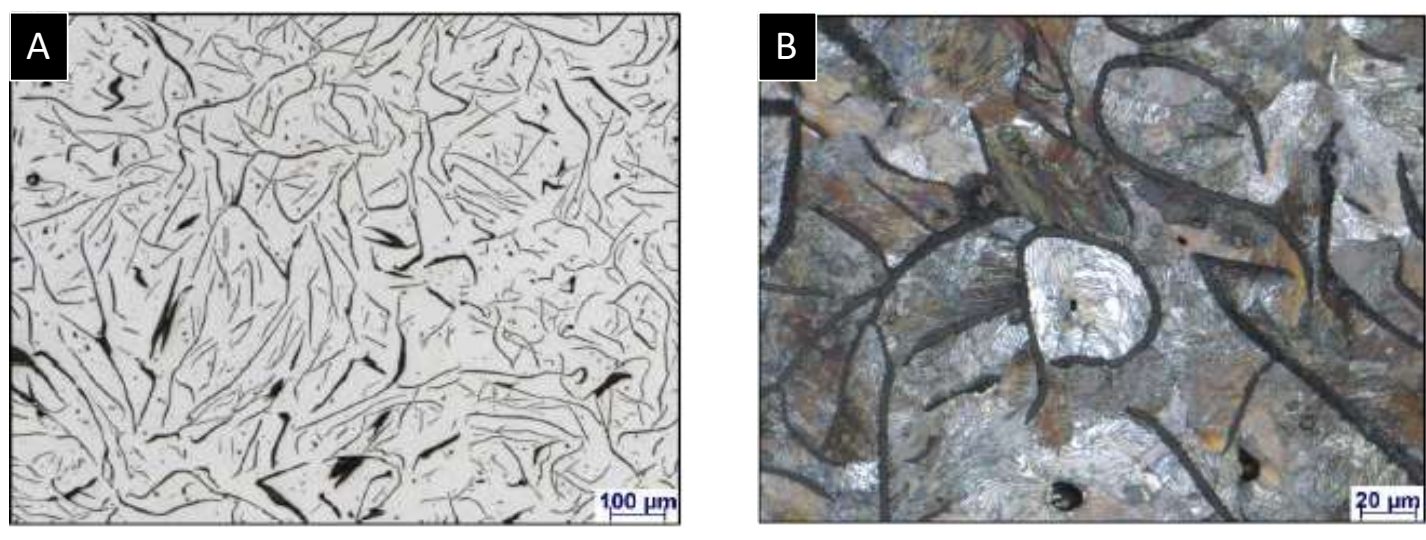

Fonte: Autor (2020).

Figura 9 - Análise metalográfica para o corpo de prova de liga base $+0,10 \% \mathrm{Nb}$ sem ataque (a) e com ataque Nital 5\% (b).
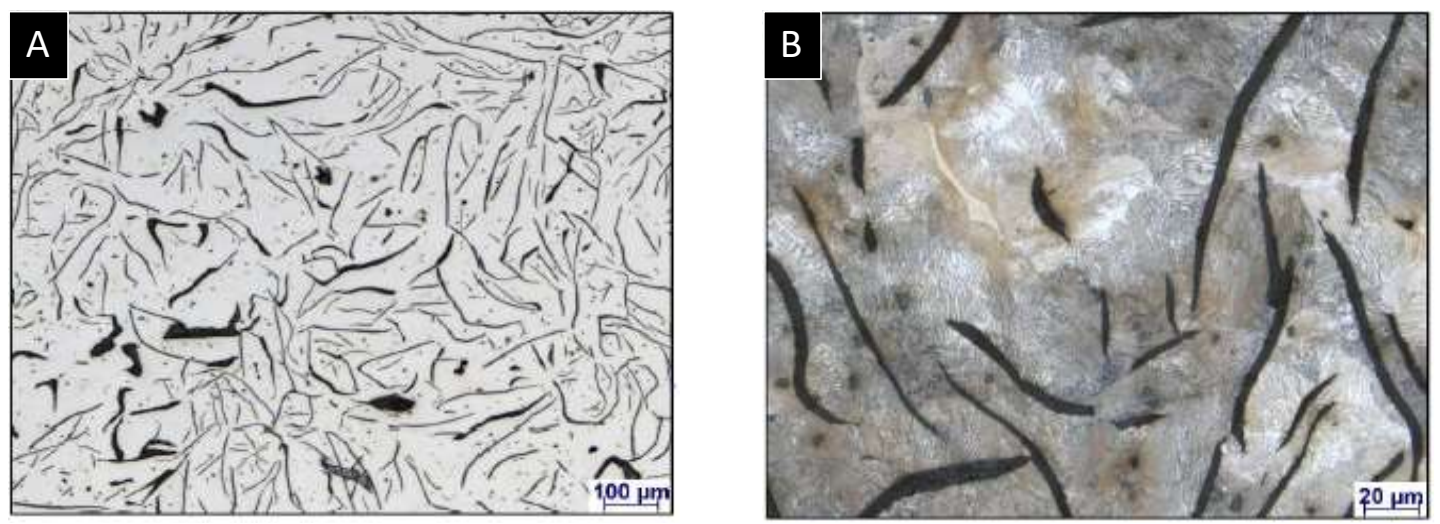

Fonte: Autor (2020). 
Figura 10 - Análise metalográfica para o corpo de prova da liga base $+0,20 \% \mathrm{Nb}$ sem ataque (a) e com ataque $\mathrm{Nital} 5 \%$ (b); presença de carbonetos tipo $\mathrm{NbC}$ (c).
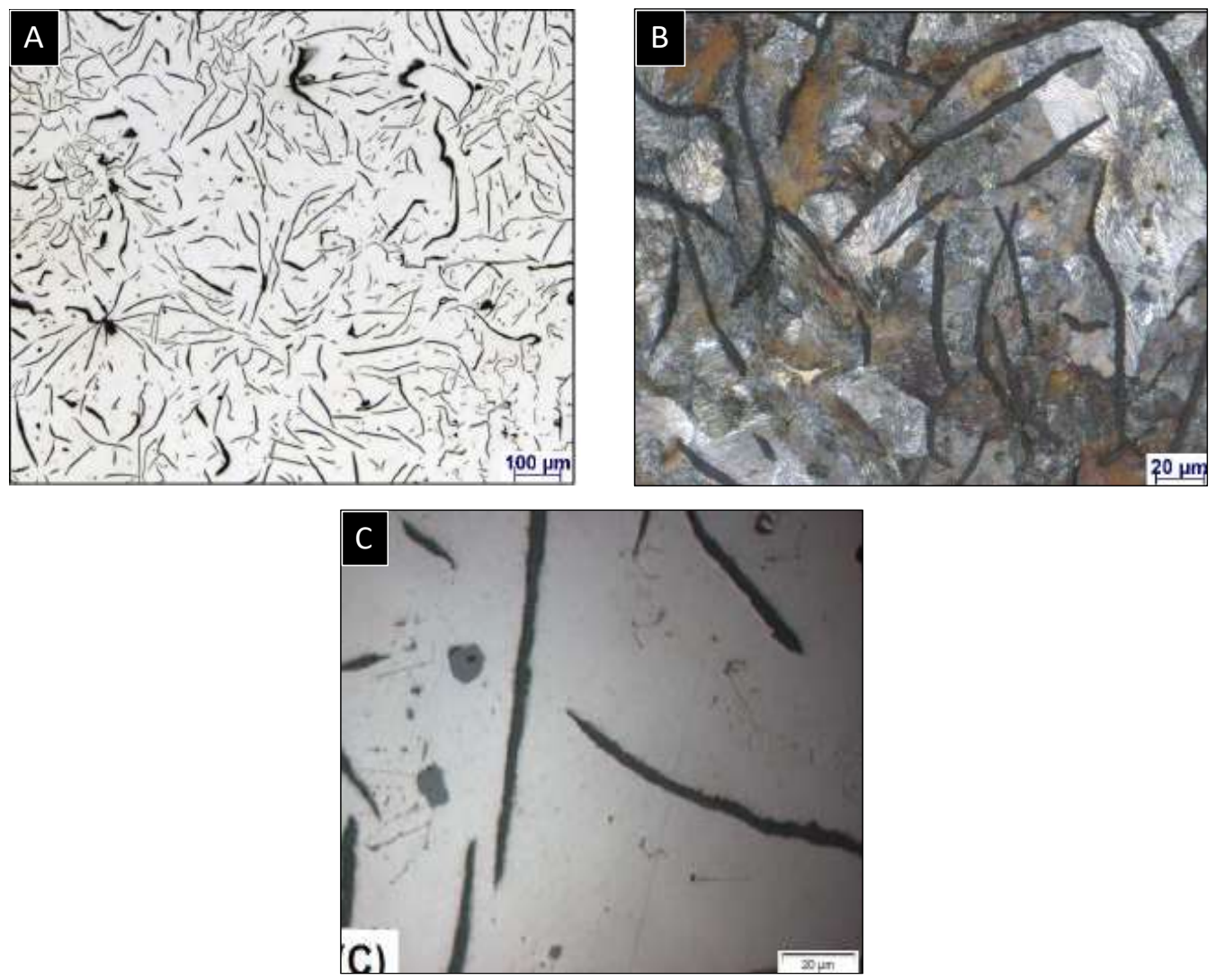

Fonte: Autor (2020).

Figura 11 - Análise metalográfica para o corpo de prova da liga base + 0,15\% Mo sem ataque (a) e com ataque Marble (b).
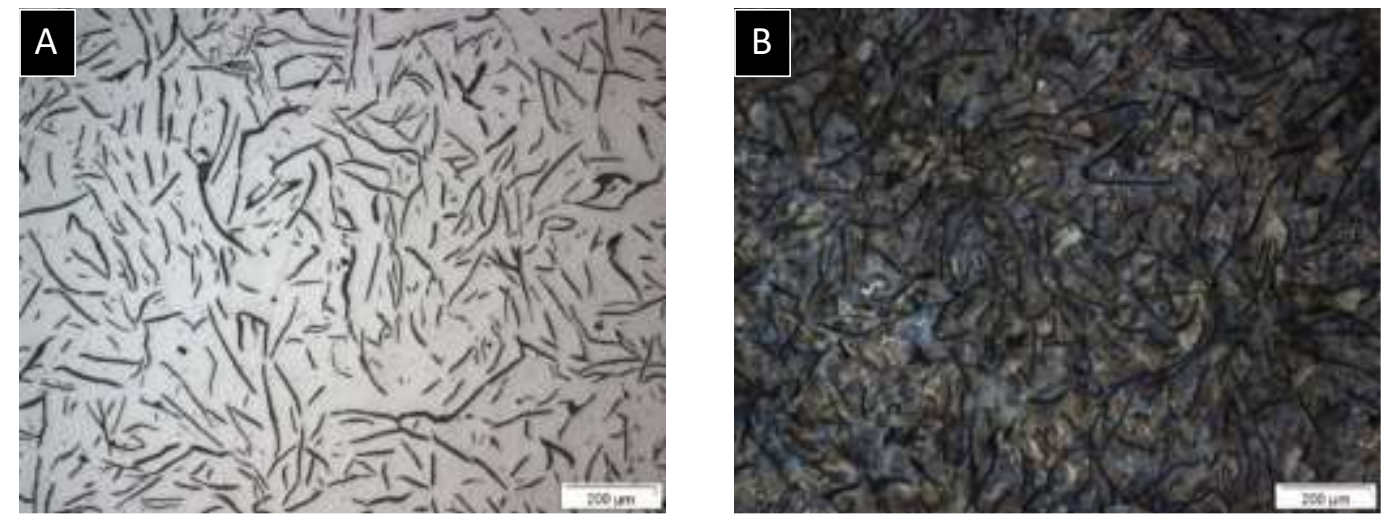

Fonte: Autor (2020).

\subsection{Células eutéticas}

A composição da liga base apresentou um número médio de $203 \pm 40$ Cel.cm-2 ${ }^{2}$, valor ligeiramente inferior ao da liga base $+0,10 \% \mathrm{Nb}$ que teve resultados de $215 \pm 40$ Cel.cm- ${ }^{2}$. Comparando-se a liga base com as ligas que tiveram $0,20 \% \mathrm{Nb}$ e 0,15\% Mo adicionados, nessas ligas, o aumento de células foi de 23,2\% aproximadamente, evidenciando-se um possível efeito de nucleação e modificação na estrutura. Mohrbacher e Zhai (2011) afirmaram que pequenas partículas residuais de NbC permanecem durante o resfriamento e agem como núcleos heterogêneos de nucleação para o grafita na reação eutética, proporcionando um aumento da taxa de nucleação e modificando a morfologia da grafita resultante e o tamanho da célula eutética. A Figura 12 mostra as células eutéticas dos corpos de prova deste estudo. 
Figura 12 - Análise metalográfica de quantificação das células eutéticas.
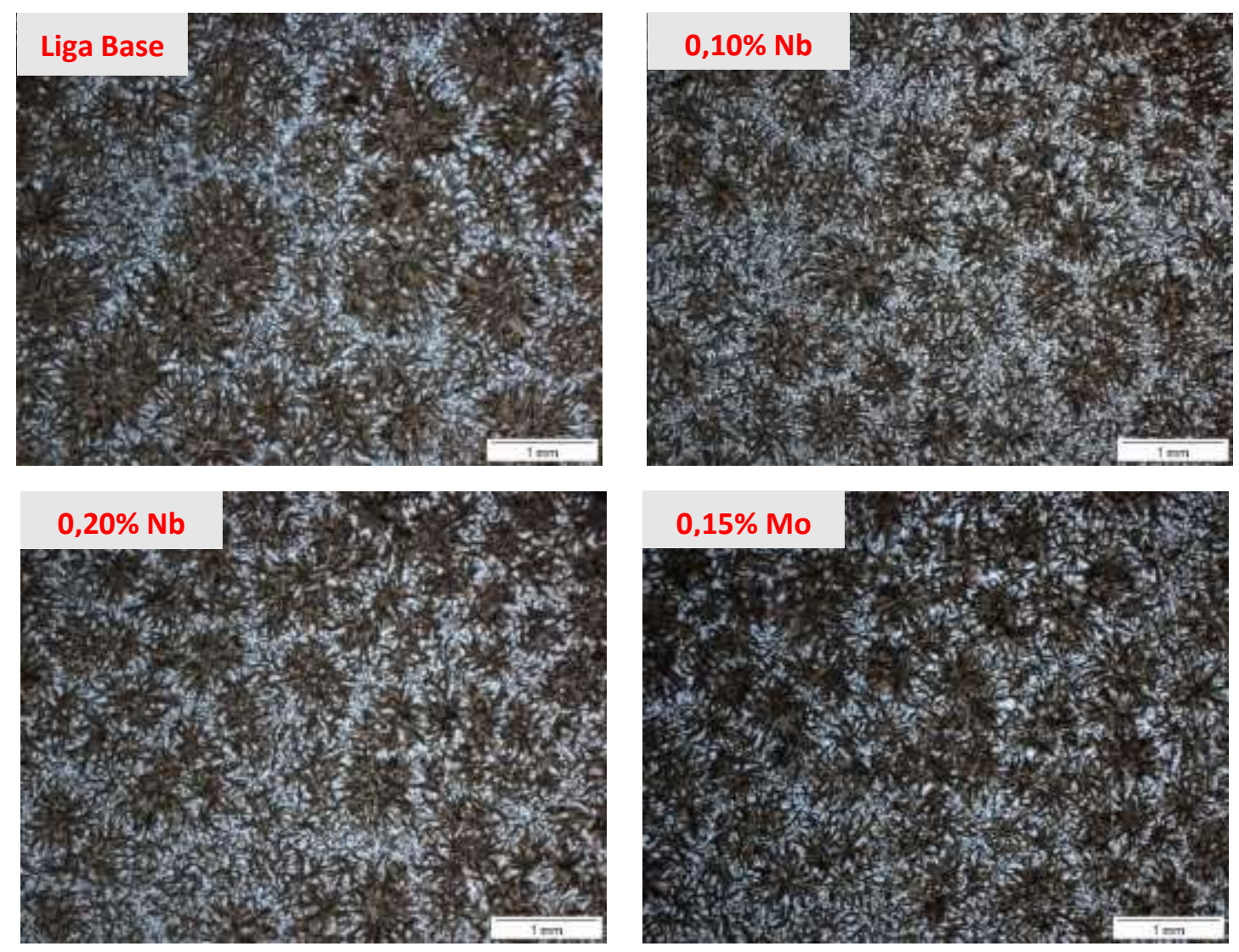

Fonte: [Adaptado de] Relatório Senai Sistema FIEMG CETEC (2020)

\subsection{Composição química}

A Tabela 4 mostra os resultados das análises químicas obtidas.

Tabela 4 - Resultados da análise química das corridas de ferro fundido cinzento com adição de nióbio e molibdênio.

\begin{tabular}{|c|c|c|c|c|c|c|c|c|c|c|c|c|}
\hline $\begin{array}{c}\text { Elementos } \\
(\%)\end{array}$ & C & $\begin{array}{c}\text { Si } \\
\text { Base }\end{array}$ & $\mathbf{S i}$ & Mn & $\mathbf{P}$ & $\mathbf{S}$ & $\mathrm{Cr}$ & $\mathbf{C u}$ & Sn & $\mathbf{N b}^{*}$ & Mo* & $\mathrm{Ceq}^{* *}$ \\
\hline Liga base & 3,81 & 1,47 & 1,80 & 0,45 & 0,05 & 0,08 & 0,13 & 0,32 & 0,03 & $<0,01$ & $<0,01$ & 4,43 \\
\hline $\begin{array}{c}\text { Liga base } \\
+0,10 \% \\
\mathrm{Nb} \\
\end{array}$ & 3,84 & 1,46 & 1,84 & 0,44 & 0,05 & 0,09 & 0,12 & 0,32 & 0,03 & 0,08 & $<0,01$ & 4,47 \\
\hline $\begin{array}{c}\text { Liga base } \\
+\mathbf{0 , 2 0 \%} \\
\mathrm{Nb}\end{array}$ & 3,77 & 1,36 & 1,72 & 0,42 & 0,04 & 0,08 & 0,10 & 0,27 & 0,02 & 0,22 & $<0,01$ & 4,35 \\
\hline $\begin{array}{c}\text { Liga base } \\
+0,15 \% \\
\text { Mo }\end{array}$ & 3,72 & 1,41 & 1,80 & 0,48 & 0,04 & 0,08 & 0,13 & 0,38 & 0,03 & 0,01 & 0,15 & 4,33 \\
\hline
\end{tabular}

*Elementos de liga adicionados de acordo com as Tabelas 1 e 2, já apresentadas neste estudo: Adição de 0,10\% Nb, 0,20\% Nb e 0,15\% Mo **O percentual de carbono equivalente foi obtido através do (Ceq) Fonte: Autor (2020).

Foi possível observar que os elementos manganês, fósforo, enxofre, cromo, nióbio e molibdênio estão dentro da especificação. Houve um pequeno desvio no resultado de estanho, silício, cobre, porém não impactando na formação do ferro fundido, considerando que para este estudo as faixas especificadas foram extremamente reduzidas para garantir a qualidade e 
reduzir a variabilidade do processo produtivo. O elemento carbono apresentou uma pequena variação acima da especificação para as corridas de liga base e liga base com adição de nióbio $0,10 \%$. O resultado do teor de silício ficou inferior à meta na corrida com adição de nióbio de $0,20 \%$.

\subsection{Difusividade térmica}

A Figura 13 apresenta o gráfico dos resultados de difusividade térmica nas temperaturas de $380^{\circ} \mathrm{C}, 480^{\circ} \mathrm{C}, 580^{\circ} \mathrm{C}$ e $680^{\circ} \mathrm{C}$, referentes às ligas denominadas liga base, liga base $+0,10 \% \mathrm{Nb}$, liga base $+0,20 \% \mathrm{Nb}$ e liga base $+0,15 \% \mathrm{Mo}$. Notase que a difusividade diminui com o aumento da temperatura em todas a ligas deste estudo, confirmando os dados de literatura.

Figura 13 - Ensaio de difusividade térmica nas temperaturas de $380^{\circ} \mathrm{C}, 480^{\circ} \mathrm{C}, 580^{\circ} \mathrm{C}$ e $680^{\circ} \mathrm{C}$, referentes às ligas: base, base $+0,10 \% \mathrm{Nb}$, base $+0,20 \% \mathrm{Nb}$ e base $+0,15 \% \mathrm{Mo}$.

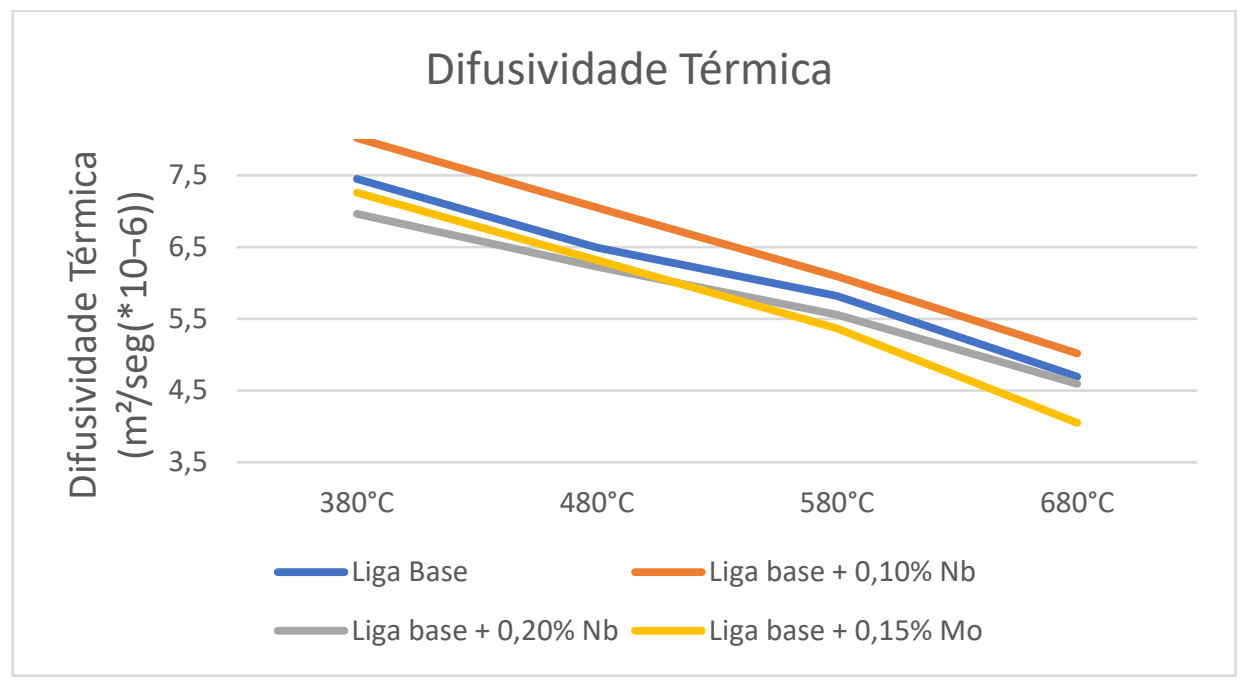

Fonte: Autor (2020).

A liga denominada liga base $+0,10 \% \mathrm{Nb}$ apresenta um resultado melhor de difusividade em todas as temperaturas, fato que pode ser atribuído à maior quantidade de grafita associada à adição de $0,10 \%$ de nióbio. Isso pode ser confirmado comparando-se o resultado da liga com adição de $0,10 \% \mathrm{Nb}$ e o resultado da liga base, onde observou-se uma quantidade similar de grafita por área. Porém, os valores de difusividade na liga base foram inferiores ao da liga base $+0,10 \% \mathrm{Nb}$. As ligas denominadas, liga base $+0,20 \% \mathrm{Nb}$ e liga base $+0,15 \%$ Mo apresentaram valores de difusividades menores em relação à liga base e à liga base $+0,10 \% \mathrm{Nb}$, em todas as temperaturas, fator atribuído à menor quantidade de grafita por área e à maior presença de carbonetos. A difusividade térmica é um dos principais parâmetros para dimensionamento do material a ser utilizado na fabricação do ferro fundido cinzento utilizado em discos de freios automobilísticos, pois descreve a taxa de propagação do calor.

\section{Conclusões}

Após a apresentação e a discussão dos resultados, verifica-se que a adição de nióbio ou molibdênio no ferro fundido cinzento, aplicado ao seguimento de discos de freios automobilísticos, melhora as propriedades mecânicas na temperatura ambiente e nas temperaturas de $380^{\circ}, 480^{\circ}, 580^{\circ}$ e $680^{\circ} \mathrm{C}$.

O teste realizado com a liga 3 de ferro fundido cinzento (liga base $+0,20 \%$ de $\mathrm{Nb}$ ) e o teste 4 (liga base $+0,15 \% \mathrm{Mo}$ ) apresentaram resultados de resistência à tração em todos os ensaios realizados nas temperaturas ambiente, $380^{\circ} \mathrm{C}, 480^{\circ} \mathrm{C}, 580^{\circ} \mathrm{C}$ e $680^{\circ} \mathrm{C}$ estatisticamente iguais, obtendo valores superiores de 25 a $40 \%$ em relação ao teste 1 (liga base) e de 10 a $15 \%$ acima do teste 2 (liga base $+0,10 \%$ de $\mathrm{Nb}$ ). $\mathrm{O}$ teste 2 apresentou também resultados de resistência à tração superiores ao teste 1 (liga 
base) obtendo valores acima de 10 a 38\%, podendo ser uma excelente alternativa econômica para aplicações susceptíveis a temperaturas elevadas, principalmente para temperaturas de trabalho de até $580^{\circ} \mathrm{C}$. Quando adicionados os elementos de liga nióbio ou molibdênio na liga base, houve um aumento na dureza Brinell, pois estes elementos são fortes formadores de carbonetos de alta dureza e ainda promovem o refino do espaço interlamelar da perlita, fato que contribui significativamente com os resultados de dureza. Através dos ensaios de difusividade, pôde-se observar que a liga denominada liga base $+0,10 \%$ $\mathrm{Nb}$ apresenta um resultado melhor de difusividade em todas as temperaturas testadas $\left(380^{\circ} \mathrm{C}, 480^{\circ} \mathrm{C}, 580^{\circ} \mathrm{C} \mathrm{e} 680^{\circ} \mathrm{C}\right)$, fato este que pode ser atribuído à maior quantidade de grafita associada à adição de um teor de nióbio de 0,10\% .

Os resultados obtidos neste estudo estimulam a realização de uma análise tribológica para aplicação em discos de freios, com foco nos quatro materiais de discos testados e no material de atrito, abordando à avaliação do coeficiente de atrito dos materiais, a resistência ao desgaste conforme Norma SAE J 2707, à avaliação do ruído, vibração, aspereza e o desempenho na utilização conjugada de $\mathrm{Nb}, \mathrm{Mo}, \mathrm{Cr}, \mathrm{Cu}$ e $\mathrm{Sn}$.

\section{Referências}

ABNT (1981) NBR.8583. Peças em Ferro Fundido Cinzento Classificadas Conforme a Dureza Brinell (NBR)

ABNT (1986) NBR.6589. Peças em Ferro Fundido Cinzento Classificadas Conforme a Resistência à Tração (NBR)

ASTM (2017) A 247. Test Method for Evaluating the Microstructure of Graphite in Iron Castings (ASTM)

ASTM (2016) A 48/A48M. Standard Specification for Gray Iron Castings (ASTM).

ASTM (2011) E1019:2011. Standard Test Methods for Determination of Carbon, Sulfur, Nitrogen, and Oxygen in Steel, Iron, Nickel, and Cobalt Alloys by Various Combustion and Fusion Techniques (ASTM).

Bertoli, C., \& Rohrig, K. (1981). Seleção e Efeitos Gerais de Elemento de Liga em Ferros Fundidos Cinzentos e Nodulares. Revista Fundição.

Callister Júnior. W. D. (2002). Ciência e Engenharia de Materiais: Uma Introdução. (5ª ed.); LTC.

Chen, X., Xu, J., Hu, H., Mohrbacher, H., Kang, M., Zhang, W., Guo, A., \& Zhai, Q. (2017). Effects of Niobium Addition on Microstructure and Tensile Behavior of as Cast Ductile Iron. Revista Materials Science and Engineering.

Chen, H. X., Chang, Z. C, LU, J. C., \& Lin, H. T. (1993) Effect of Niobium on Wear Resistance of 15\% Cr White Cast Iron. Wear.

Chiaverini. V. (2015). Aços e Ferros Fundidos: Ferro Fundido. (7ª ed.) rev. São Paulo: ABM.

Chiaverini, V. (1986). V. Tecnologia Mecânica. (2ª ed.) São Paulo: McGraw-Hill Ltda.

Colpaert, H. (1983). Metalografia dos Produtos Siderúrgicos Comuns: Ferros Fundidos comuns. (3a. ed.) rev. São Paulo: Blucher.

Founding grey cast iron EN 1561 (1997). British Standard. This document specifies the characterizing properties of grey cast irons, thickness, tensile strength, hardness, thermal conductivity, electrical resistivity, coercivity, permeability, Brinell hardness measurement, symbols, grades (quality) (DIN).

Gasparin, H. D., et al. (2014). Propriedades Mecânicas a Altas Temperaturas de Ferros Fundidos Cinzentos Aplicados a Cabeçotes de Motor a Diesel. In: 69 Congresso Anual Da Abm, 2014, São Paulo. Anais do Congresso Anual da ABM, São Paulo, 69 (69).

Guesser, W. L., Krause, W., \& Pieske, (1984). A. A Fragilização Intergranular de Ferros Fundidos de Alta Ductilidade., 40 (322), Revista ABM.

Guesser, W. L., Masiero, I., Melleras, E., \& Cabezas, C. (2004). Fatigue Strength of Gray Iron and Compacted Graphite Iron Used for Engine Cylinder Blocks. SAE Brasil, São Paulo.

Guesser, W. L., \& Hilário, D. G. (1999). Ferros Fundidos Nodulares Perlíticos. Contribuição ao CONAF 99, ABIFA, São Paulo, out.

Guesser, W. L. (2009). Propriedades Mecânicas dos Ferros Fundidos. (1ª. ed.): Blücher.

Guesser, W. L., Masiero, I., Melleras, E.\& Cabezas, C. S. (2005). Thermal Conductivity of Gray Iron and Compacted Graphite Iron Used for Cylinder Heads, Revista Matéria., 10 (2).

Huang, W, Qiang, G., Yanan, Z., Yaning, Z., Haibo, L., Haonan, R., Yamei, Z., \& Xuefei, H. (2020) Influence of Sn and Nb Additions on the Microstructure and Wear Characteristics of a Gray Cast Iron. Revista Materials Science \& Processing

Hasse, S. (1996). Duktiles Gusseisen. Berlin: Schiele \& Schon

ISO 185:2019 (2019). Grey Cast Iron Classification. This Document Specifies the Characterizing Properties of Grey Cast Irons (ISO)

Kanno, T. (2005). Effect of Alloying Elements on the Eutectic Temperatures in Cast Iron. AFS, 113. 
Maluf, O. (2017) Fadiga Termomecânica em Ligas de Ferro Fundido Cinzento para Discos de Freios Automotivos. Tese (Doutorado). USP São Carlos,

Maluf, O. et al. (2009). Effects of Alloying Elements on Thermal Diffusivity of Gray Cast Iron Used in Automotive Break Disks. Journal of Materials Engineering and Performance, 18 (7).

Medeiros, M. A. (2010). Elemento Químico Ferro. Química Nova, 32.

Milan, M. T., Maluf, O., Spinelli, D., \& Bose Filho, W. W. (2004). Metais: Uma Visão Objetiva. São Carlos: Suprema.

Mohrbacher, H. (2007). Grain Size Control by Niobium Microalloying in Gear Steel during High Temperature Carburizing. NiobelCon, Belgium.

Mohrbacher, H., \& Zhai, Q. (2011) Niobium Alloying in Gray Cast Iron for Vehicle Brake Discs. In: AIST Steel Properties and Applications, Materials Science and Technology, 137-148.

Pieske, A., Chaves Filho, L. M., \& Reimer, J. F.(1980). Ferros Fundidos Cinzentos de Alta Qualidade. (3a. ed.) Joinville.

Pieske, A, Chaves Filho, L. M., \& GruhL, A. (1975). As variáveis metalúrgicas e o controle da estrutura de ferros fundidos cinzentos, Revista Metalurgia ABM, Relatório Senai sistema fiemg cetec. (2020) Avaliação de Ferro Fundido Cinzento Eutético com Adição de Nióbio para Trabalho a Quente.

Rosario, A. M. (2012). Estudo dos Efeitos de Elementos de Liga na Solidificação de um Ferro Fundido Cinzento Via Análise Térmica. Tese (Doutorado). Universidade Estadual de Ponta Grossa.

Santos, A. B. S., \& Castelo, B. C. H. (1991) Metalurgia dos Ferros Fundidos Cinzentos e Nodulares. São Paulo: IPT.

Santos, A. B. S., \& Branco, C. H. C. (1989). Metalurgia dos ferros fundidos cinzentos e nodulares. São Paulo, IPT.

Sinatora, A., \& Santos, A. B. S. (1976). Efeito da porcentagem de Fe-Si utilizado como inoculante na estrutura e propriedades de ferro nodular, Metalurgia.

Turnbull, G. K., \& Wallace, J. F. (1959). Molybdenum Effect on Gray Iron Elevated Temperature. AFS, 67.

Unisociesc. Ferro Fundido Cinzento. (2017). Apostila. Pós-graduação em Metalurgia, Sociedade Educacional de Santa Catarina - UNISOCIESC, Joinville.

Van vlack, L. H. (2000). Princípio de Ciências dos Materiais. (13ª ed.) rev. São Paulo: Blucher.

Zhai, Q., Zhou, W., Zhu, H., Zheng, D., Zheng, H., \& Hua Q. (2011). Niobium Alloying Effect in High Carbon Equivalent Grey Cast Iron., 8 (1), Revista China Foundry.

Wang, H. (1999). The Effect of Graphite Flake Morphology on the Thermal Diffusivity of Gray Cast Irons Set for Automotive Brake Discs, Revista Materials Science.

Zhang, J. T., \& Ren, F. Z (2013). Study on the Influences on Microstructure and Properties of High-Strength Grey Cast Iron in Addition to Alloying Elements $\mathrm{Nb}$, Revista Materials Research, 221-224.

Zhong, L., Xu, Y., \& Ye, F (2012). In Situ NbC Particulate-Reinforced Iron Matrix Composite: Microstructure and Abrasive Wear Characteristics. Tribology Letters, 47 (2). 